\section{Coadministration of ibuprofen/caffeine on bleaching- induced tooth sensitivity: A randomized clinical trial}

\author{
Karine Letícia da Silva (D1, Elisama Sutil (D1, Diego Hortkoff (D) 1, \\ Renata Maria Oleniki Terra (D) 1, Márcia Rezende (D2, Alessandra \\ Reis (D) 1, Alessandro D. Loguercio (D), Ana Paula Vilela (D) 3, Paulo \\ Vitor Farago 3.
}

This clinical trial evaluated the effect of the coadministration of ibuprofen/caffeine on bleaching-induced tooth sensitivity (TS). A triple-blind, parallel-design, randomized clinical trial was conducted on 84 patients who received ibuprofen/caffeine or placebo capsules. The drugs were administered for 48 hours, starting 1 hour before the in-office bleaching. Two bleaching sessions were performed with $35 \%$ hydrogen peroxide gel with 1-week interval. TS was recorded up to 48 hours after dental bleaching with a 0-10 visual analogic scale (VAS) and a 5-point numeric rating scale (NRS). The color was evaluated with VITA Classical and VITA Bleachedguide scales ( $\triangle \mathrm{SGU}$ ) and VITA Easyshade spectrophotometer $\left(\triangle \mathrm{E}^{*} \mathrm{ab}\right.$ and $\left.\triangle \mathrm{E} 00\right)$. The absolute risk of TS in both groups was evaluated using Fischer's exact test. Comparisons of the TS intensity (NRS and VAS data) were performed by using the Mann-Whitney test and a two-way repeated measures ANOVA, respectively. The color alteration between the groups was compared with the Student's t test. The significance level was 5\%. There was no statistically significant difference between the groups for the absolute risk of TS $(p=1.00)$ or for the intensity of TS $(p>0.05)$. A bleaching of approximately 7 shade guide units was observed on the Vita Classical and Vita Bleachedguide scales, with no statistical difference between the groups. It was concluded that coadministration of ibuprofen and caffeine did not reduce the absolute risk or intensity of TS and did not interfere with the efficacy of dental bleaching.

\author{
${ }^{1}$ School of Dentistry. State University of Ponta \\ Grossa, Ponta Grossa, Paraná, Brazil \\ ${ }^{2}$ School of Dentistry. School Paulo Picanço, \\ Fortaleza, Ceará, Brazil.
}

${ }^{3}$ School of Pharmacy, State University of Ponta Grossa, Ponta Grossa, Paraná, Brazil.

\author{
Correspondence: Alessandro Dourado Loguercio \\ Rua Carlos Cavalcanti, 4748 Bloco M, Sala 64- \\ A; Uvaranas, Ponta Grossa, Paraná, Brazil \\ 84030-900; Work Telephone Numbers: 42 \\ 32203741 \\ e-mail: aloguercio@hotmail.com
}

\title{
Introduction
}

The popular concern for esthetics has also reflected in the Dentistry. The search for the perfect smile increased the demand for dental bleaching, making it one of the most requested procedures by patients who want a whiter and perfect smile.

Among dental bleaching techniques, the in-office approach use peroxides with concentrations from $15 \%$ to $38 \%$, as it allows a lower time of treatment when compared with the at-home bleaching (1). In addition, the procedure is controlled by professional, which avoids the ingestion of the bleaching gel and the exposure of the material to the soft tissues (2), making the procedure safe and effective.

However, adverse effects such as tooth sensitivity and gingival irritation may eventually be observed when dental bleaching is performed (2). Bleaching-induced tooth sensitivity (TS) is the most common adverse effect (2-4) of the bleaching procedure and it was occur during bleaching up to 48 hours after. In some cases the TS can be severe, leading the patient to abandon the treatment (3). It is accepted that the bleaching-induced TS occurs because peroxides when reach the pulp, produces an inflammatory reaction, with release of inflammation mediators (5) responsible for local vasodilation, increased vascular permeability, and mild to moderate TS.

Therefore, over the past years, studies have been carried out in order to find out alternatives to reduce the bleaching-induced TS. Some studies that employed oral medications, with systemic action, to inhibit the release of inflammatory mediators did not reduce the absolute risk of TS $(3,6)$. Although systematic reviews of randomized clinical trials demonstrate that the preventive analgesia with antiinflammatory drugs (NSAIDs) and analgesic drugs applied alone did not reduce the absolute risk or intensity of TS after the bleaching procedure (7-9), not all types of available drugs and their combination were evaluated in randomized clinical trials. 
Actually, Ibuprofen, a COX inhibitor, was shown to reduce the TS intensity during and up to $1 \mathrm{~h}$ after bleaching, but not in hours subsequent to bleaching $(3,6)$. According to Paula et al. $(3)$, the lack of efficacy of ibuprofen to prevent TS for more time may be related to the fact that other inflammatory mediators are involved in the inflammatory reaction of the pulp. By associating ibuprofen to an analgesic or another anti-inflammatory drug, one could increase the pain relief to longer times after in-office bleaching. As demonstrated in other trials, the association of ibuprofen with other analgesic or antiinflammatory drugs could increase its analgesic efficacy $(10,11)$.

Caffeine was used in combination with ibuprofen, and at low doses was able to increase the analgesic efficacy in headache (10) and extractions of third molars (11). It operates in several pain mechanisms such as the blockade of inflammatory hypernociception and GABA receptors, inhibition of the phosphodiesterase enzyme and increase in the effect of catecholamines $(11,12)$. In addition, caffeine can modify the mood and change the perception of pain (12).

Administration of ibuprofen with caffeine may increase the ibuprofen concentration in the blood, causing rapid absorption and increased analgesic effect, allowing a fast pain relief, with prolonged action. A synergistic effect can perhaps be observed with the combination of these drugs. It is expected that co-administration of ibuprofen/caffeine and its administration for $48 \mathrm{~h}$ after bleaching may promote a greater reduction in intensity/risk of TS than that observed in previous studies. In addition, inflammatory mediators involved in the pulp inflammation during bleaching could be inhibited, allowing the blockage of pain signaling produced by in-office bleaching.

Therefore, the aim of this parallel, triple-blind RCT was to evaluate the effect of the coadministration of ibuprofen $400 \mathrm{mg}$ and caffeine $100 \mathrm{mg}$ on the reduction of TS produced by in-office bleaching with $35 \%$ hydrogen peroxide. Furthermore, we tested the hypothesis that the coadministration of ibuprofen/caffeine would not affect the risk of bleaching-induced TS (primary outcome). Also, the intensity of TS and color change were evaluated.

\section{Material and methods}

Ethics approval and approval registration

The protocol established by the Consolidated Standards of Reporting Trials statement 2019 (13) (CONSORT) was used to report the present study. This RCT was approved (protocol number 2.789.881) by the Scientific Review Committee for the Protection of Human Participants of the State University of Ponta Grossa (Ponta Grossa, Brazil). The research protocol was registered in the Brazilian Clinical Trials Registry (ReBEC) under the identification number RBR-48C9XT. All the participants were informed about the nature and objectives of the study before being allocated to the study groups and they signed an informed consent form.

\section{Trial design, setting and locations of data collection}

This clinical trial was performed from March to April 2019, in the Clinics of the School of Dentistry at the State University of Ponta Grossa. This was a randomized, parallel, placebo-controlled clinical trial.

\section{Sample size calculation}

The sample size was calculated on the website www.sealedenvelope.com, based on the primary outcome of absolute risk of TS (number of patients [percent] who reported pain at some point during dental bleaching). The absolute risk of TS was reported to be approximately $93 \%$ for the bleaching product Whiteness HP AutoMixx (FGM Prod. Odont. Ltda, Joinville, Brazil) (14). The calculation was performed for a superiority trial with a binary outcome, so, to be able to detect a difference of $25 \%$ between the placebo group and the reference group, a minimal sample size of 72 patients was required for a power of $80 \%$, and an alpha of 5\%. Sample size was increased in approximately $15 \%$ to compensate for the eventual loss of patients.

\section{Recruitment}

Recruitment were performed through social media advertising and by posting written advertisements on the university walls. All the participants signed an informed consent form before being enrolled in the study. Before the start of the bleaching procedure, all the volunteers received a dental prophylaxis with pumice powder and water in rubber cups. 


\section{Eligibility criteria}

The volunteers of this study were adults with at least 18 years old and good oral and general health. The participants should have six maxillary and mandibular anterior teeth without caries lesions, restorations or endodontic treatment. The canine shade should be A2 or darker, according by a valueoriented shade guide (VITA Classical Shade, VITA Zahnfabrik, Bad Säckingen, Germany).

Participants with previous tooth sensitivity (checked with air stream application or probing), anterior restorations or dental prosthesis, with orthodontics apparatus, bruxism habits, with severe internal dental discoloration (fluorosis, tetracycline stains, pulpless teeth), recessed or exposed dentine or participants who had undergone previous dental bleaching procedures were not included in the study. In addition, pregnant and lactating women, smokers, participants with some health problems in the stomach, kidney, heart, or liver and participants with continuous use of anti-inflammatory or analgesic drugs, diabetes, hypertension or antihypertensive drugs, or allergies to ibuprofen and lactose were also excluded from the study.

\section{Random sequence generation and allocation concealment}

A blocked randomization (block sizes of 2 and 4) with an equal allocation ratio was generated in a freely available website (www.sealedenvelope.com). The distribution of the groups was recorded on sequentially numbered cards, which were placed in black opaque consecutively numbered, and sealed envelope. The information contained in the envelopes was only revealed 1 hour before the implementation of the treatment.

\section{Blinding}

This was a triple-blind clinical trial. The operators and patients were blinded to the group assignment. The evaluators, who evaluated color changes, were also blinded. To guarantee blinding, the capsules of placebo and ibuprofen/caffeine were identical and the drug packs were similar in both groups. The drugs packs were previously identified by the letters A and B by a researcher not involved in the study implementation.

The randomization process, delivery, and guidance on the administration of the drugs was performed by a third person not involved with the implementation and evaluation of the treatment.

\section{Study intervention}

The capsules containing ibuprofen/caffeine or placebo were manipulated in the Allopathic Pharmaceutics Laboratory of the State University of Ponta Grossa, with the help of qualified professional. The maximum daily dosages of the association ibuprofen $400 \mathrm{mg} / \mathrm{caffeine} 100 \mathrm{mg}$ was based on the recommendations of the Food and Drug Administration (FDA) (15). The capsules of placebo contained an inert excipient (0.05\% magnesium stearate, $1 \%$ silica colloidal gel, 1\% sodium sulfate lauryl, 30\% pharmaceutical talc, starch q.s.t 100\%).

One hour before in-office bleaching, the envelope containing the assigned group were opened, and the drug (ibuprofen/caffeine or placebo) given to the patient. Five extra doses were administered every eight hours for a period of $48 \mathrm{~h}$, in order to keep a safe maximum daily dosage of the drug (15).

One hour post-drug administration, a lip retractor (Arcflex, FGM Dental Products, Joinville, Brazil), and a light-cured gingival barrier (Top Dam, FGM Dental Products, Joinville, Brazil) was placed on the gingival tissue of the teeth to be bleached (from second left premolar to second right premolar of the upper and lower arch). The gingival barrier was light-cured for $10 \mathrm{~s}$ (in each tooth area) at $1000 \mathrm{~mW} / \mathrm{cm}^{2}$ (Radii-Cal, SDI, Bayswater, Australia).

A 35\% hydrogen peroxide gel (Whiteness HP AutoMixx, FGM, Joinville, Brazil) was applied on the dental surfaces and kept for 50 min. Two bleaching sessions were performed with a 1-week interval. All patients were instructed to brush their teeth regularly with fluoridated toothpaste. The patients were also instructed to not to use anti-inflammatory or analgesic drugs for $48 \mathrm{~h}$ post-bleaching without the consent of the investigators. In case of any adverse effects by the use of the study-drug or TS postbleaching, the patients were instructed to contact the researchers of the study. To control the drug usage during the $48 \mathrm{~h}$ post-bleaching, an only researcher sent cell phone text messages to remind the patient to take the capsule. In addition, the patient received a form containing the schedule of administration of the capsules. The patient was instructed to fill with an " $x$ " next to each administered capsule, therefore, if the patient did not administer some of the capsules, this information would be shown in the form. This form was given to the researchers in the next bleaching session. 


\section{TS evaluation}

In both sessions, the patients were instructed to record the bleaching-induced TS. The TS was recorded in four different periods: during bleaching, up to 1, up to 24, and up to 48 hours post-bleaching using two different pain scales (5-point numeric rating scale [NRS] and a 0-10 visual analogic scale [VAS] to allow comparison with studies that used them). For the NRS, the patients had to choose a score from 0 to 4 to represent the intensity of TS in which $0=$ none, $1=$ mild, $2=$ moderate, $3=$ considerable, and $4=$ severe $(14,16)$. For the VAS, the participants were instructed to mark with a vertical line across a horizontal $0-10 \mathrm{~cm}$ line, where $0=$ no sensitivity and $10=$ severe sensitivity. The distance in millimeters from the zero end was measured with the aid of a millimeter ruler.

If there was another episode in each evaluation period (for example up to 24), the patient should perform a new record. For data analysis, the higher score presented by the patient in each evaluation time was considered when there was more than one appointment in the period. For both scales, the higher score (NRS) or numeric value (VAS) obtained from both bleaching-sessions at each assessment point was used for calculation of the intensity of TS. The absolute risk of TS represented the percentage of volunteers who reported TS at least once during treatment, in both session of bleaching.

\section{Color evaluation}

Color evaluation was performed by two experienced and calibrated dentists (kappa statistics higher than 0.81 after previous calibration) not involved in the randomization procedures. For calibration, two evaluators responsible for the analyses were calibrated before starting the study. For this, a calibration was held for prior discussion on the use of the VITA Classical and VITA Bleachedguide 3D MASTER scales. Then, the color analysis of the anterosuperior teeth of 10 volunteers was performed. A new color analysis was performed four days after the first with the same volunteers. Inter-examiner agreement tests were performed using the kappa agreement measure. The two evaluators presented intra-examiner agreement indexes higher than $80 \%(0.8-1.0)$, being considered "almost perfect". If disagreements occurred during the evaluation, the evaluators needed to reach a consensus before the participant was dismissed. The color evaluation was performed at baseline, 1-week after the 1st bleaching session, 1-week after the 2nd bleaching session and 1-month after the end of the bleaching treatment.

We used three different instruments to evaluate color change: Two shade guide units named VITA Classical (Vita Zahnfabrik, Bad Sackingen, Germany) and VITA Bleachedguide 3D-MASTER (VITA Zahnfabrik) and a spectrophotometer Vita Easyshade (VITA Zahnfabrik). The 16 tabs from the Vita Classical scale was arranged in from the highest (B1) to the lowest (C4) value. The 24 tabs of VITA Bleachedguide 3D-MASTER's is already organized from the highest (0M1) to lowest (5M3) value (16). The color was evaluated at the middle third of the buccal surface of the upper canine $(14,16)$. Color changes $(\triangle \mathrm{SGU})$ were calculated as the change that occurred towards the lightest end of the shade guide at the different time assessment periods.

For color measurement with the spectrophotometer, a dense silicone (Flex-sil, Technew, Rio de Janeiro, Brazil) was used to prepare a guide with a window at the middle third of the canine, so that color evaluation could be standardized at the different time assessments. CIELab parameters was recorded, where $L^{*}$ represents the value from 0 (black) to 100 (white), $a^{*}$ represent the dimension along the red-green axis, and $b^{*}$ the dimension along the yellow-blue axis. The color change at the different time assessments was calculated using the formula for the CIELab 1976, and for CIEDE 2000.

\section{Statistical Analysis}

We employed the intention-to-treat protocol. In cases of missing data, the last observation was carried forward. Intervention effect sizes (risk ratio for the risk of TS and mean differences for color changes and TS intensity) were calculated along with the 95\% confidence interval. Additionally, hypothesis testing was performed.

The data were first analyzed using the Kolmogorov-Smirnov test to assess whether they followed a normal distribution, as well as the Bartlett's test for equality of variances to determine if the assumption of equal variances was valid. Only NRS data did not fulfill the normality requirements (not shown data). The absolute risk of TS for both groups was compared using the Fisher's exact test. The TS intensity (NRS data) of the two groups was compared using the Mann-Whitney U-test. Comparisons among times, within each group, were performed using the Friedman test. The TS intensity data obtained with the VAS scale of the two groups was compared using the Student t-test and the evaluation among times, within each group, were performed using the one-way repeated measures ANOVA. 
The difference between baseline and one-month post bleaching color change was compared between group ( $\triangle \mathrm{SGU}, \Delta \mathrm{E}^{*}$ ab and $\Delta \mathrm{E} 00$ ) using a Student t-test. In all statistical tests, the significance level was $5 \%$ and the statistician was masked to the study groups. We performed all analyses by using the software Sigma Plot version 11.0 (Systat Software, San Jose, CA, USA).

\section{Results}

Characteristics of included participants

The experimental protocols were implemented exactly as planned, and no modifications were performed. A total of 145 participants were evaluated but only 84 participants were selected (19 male and 65 female; Fig. 1). The baseline color of the participants and the distribution of the genders are described in Table 1. From the 84 participants, 2 discontinued treatment (Fig. 1) after the first session due to the lack of time for performing the bleaching procedure. However, the TS data related to this first session was collected. Five participants from the placebo group and 3 participants from the ibuprofen/caffeine group did not attend any of the control sessions (Fig. 1).

Table 1. Baseline characteristics of the participants included in this clinical trial.

\begin{tabular}{lcc}
\hline \multicolumn{2}{l}{ Baseline Characteristics of the Participants } & \\
\hline Baseline color (SGU; mean \pm SD) & & $10 \pm 2.8$ \\
Age (years; mean \pm SD) & & $24.7 \pm 6.3$ \\
Gender (female; \%) & White (\%) & 77.4 \\
Race & Black (\%) & 79.8 \\
& Mulatto (\%) & 4.8 \\
& Mul & 15.5 \\
\hline
\end{tabular}

* Abbreviations: SGU, shade guide unit measured by Vita Classical; SD, standard deviation.

Figure 1. Flow diagram of study design phases, including enrollment and allocation criteria ENROLLMENT

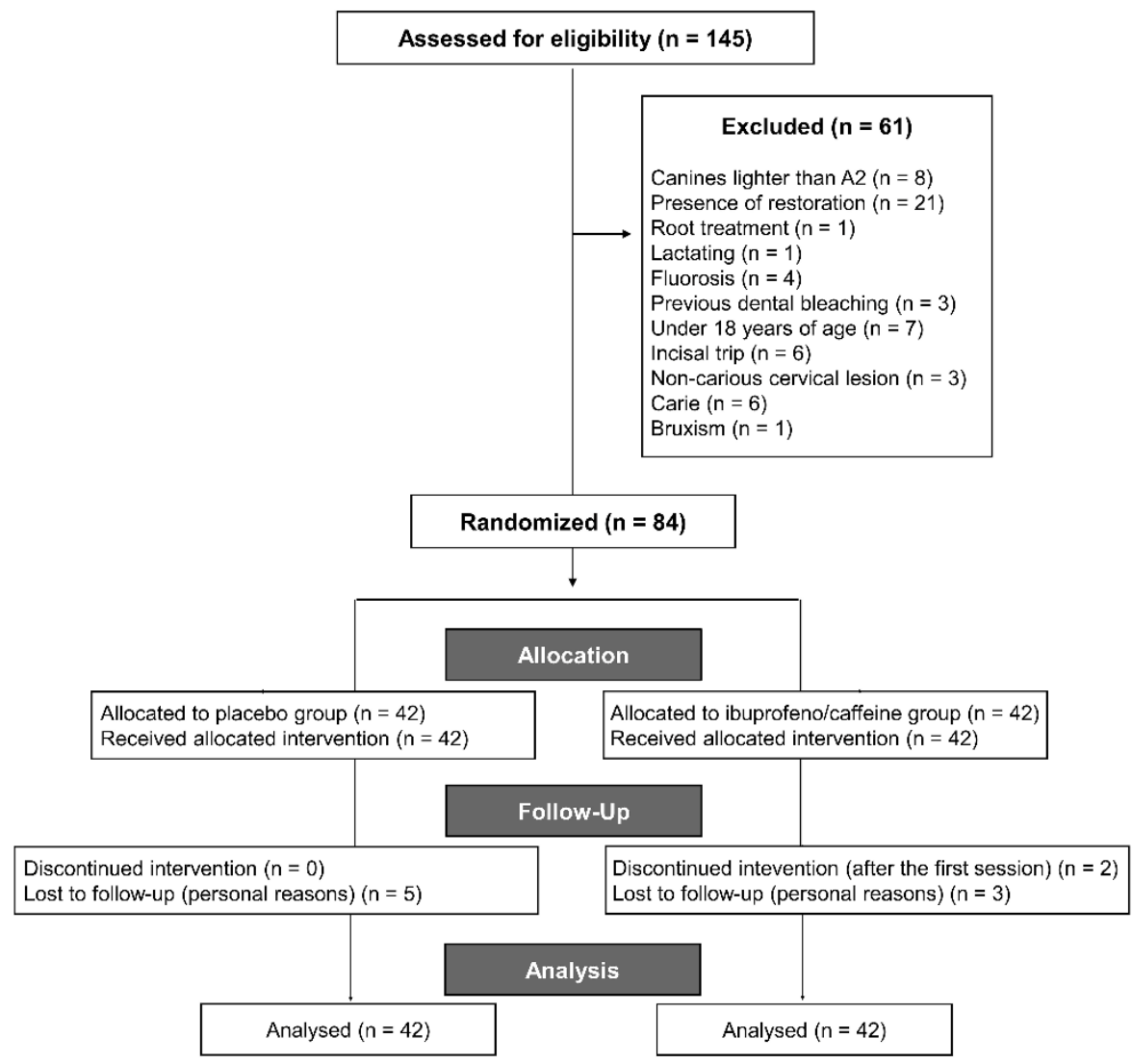


Risk of tooth sensitivity

More than $90 \%$ of the participants from both groups reported TS at least once during bleaching (Table 2). The 95\% confidence interval of the relative risk (0.97 [0.87-1.08]) crosses the null value of 1 , showing no benefit of using ibuprofen/caffeine on the reduction of TS ( $p=1.00)$.

Table 2. Comparison of the number of patients who experienced TS during the bleaching regimen in both groups along with absolute and the risk ratio*.

\begin{tabular}{ccccc}
\hline \multirow{2}{*}{ Treatment } & \multicolumn{2}{c}{$\begin{array}{c}\text { Tooth sensitivity } \\
\text { (number of participants) }\end{array}$} & & $\begin{array}{c}\text { Absolute risk } \\
(95 \% \mathrm{CI})\end{array}$ \\
\cline { 2 - 3 } Yes & No & & $92(81-97)$ & $\begin{array}{c}\text { Risk ratio } \\
(95 \% \mathrm{CI})\end{array}$ \\
\hline Ibuprofen/Caffeine & 40 & 2 & & $9.97(0.87-1.08)$
\end{tabular}

*Fisher's exact test ( $p=1.00)$.

Intensity of tooth sensitivity

Tables 3 and 4 show the TS intensity for the two pain scales. No significant difference between groups were observed for none of the pain scales. The intensity of TS was higher in the first $24 \mathrm{~h}$ after bleaching. A considerable reduction of TS was observed $48 \mathrm{~h}$ after bleaching (Tables 3 and 4).

Table 3. Medians and interquartile ranges of the TS intensity at different assessment points using the NRS scale.

\begin{tabular}{lccc}
\hline Assessment times & Ibuprofen/Caffeine $\left(^{* *}\right)$ & Placebo $\left(^{* *}\right)$ & p value (*) \\
\hline During bleaching & $1(0 / 2)^{\text {A }}$ & $1(1 / 2) \mathrm{A}$ & 0.87 \\
Up to $1 \mathrm{~h}$ & $2(1 / 3)^{\mathrm{B}}$ & $2(1 / 3) \mathrm{B}$ & 0.98 \\
Up to $24 \mathrm{~h}$ & $1(0 / 2)^{\mathrm{A}}$ & $2(1 / 2) \mathrm{A}, \mathrm{B}$ & 0.14 \\
Up to $48 \mathrm{~h}$ & $0(0 / 0)^{\mathrm{C}}$ & $0(0 / 0) \mathrm{C}$ & 0.67 \\
\hline
\end{tabular}

(*)Mann-Whitney. (**)Friedman. Within each column, significant differences are represented distinct uppercase letters.

Table 4. Means and standard deviations of the TS intensity at the different assessment points using VAS scales.

\begin{tabular}{lcccc}
\hline \multicolumn{1}{c}{ Assessment times } & Ibuprofen/Caffeine $\left(^{* *}\right)$ & Placebo $\left(^{* *}\right)$ & p value $\left(^{*}\right)$ & Mean difference (95\% CI) \\
\hline During bleaching & $2.5 \pm 2.8^{\mathrm{A}}$ & $2.0 \pm 2.5 \mathrm{~A}$ & 0.37 & $-0.5(-1.65$ to 0.65$)$ \\
Up to $1 \mathrm{~h}$ & $4.0 \pm 3.1^{\mathrm{B}}$ & $3.9 \pm 3.2 \mathrm{~A}$ & 0.83 & $-0.1(-1.47$ to 1.27$)$ \\
Up to $24 \mathrm{~h}$ & $2.7 \pm 3.1^{\mathrm{A}}$ & $2.9 \pm 3.0 \mathrm{~A}$ & 0.78 & $0.2(-1.12$ to 1.52$)$ \\
Up to $48 \mathrm{~h}$ & $0.5 \pm 1.4^{\mathrm{C}}$ & $0.4 \pm 0.9 \mathrm{~B}$ & 0.74 & $-0.1(-0.61$ to 0.41$)$ \\
\hline
\end{tabular}

(*) Student t-test. (**) One-way RM ANOVA. Within each column, significant differences are represented distinct uppercase letters.

\section{Color Change}

The inter- and intraexaminer consensus was $k=0.83$ and $k=92$ for VITA Classical scale and $k=0.87$ and $k=0.90$ for VITA Bleachedguide 3D-MASTER's scale. This high inter- and intra-examiners kappa coefficient was obtained because tabs of shade guides were combined (B1-C2, A2-D4, A3-B3 and A3,5C4 for VITA Classical scale and the same for Vita Bleachedguide 3D-MASTER's (0M1-1M, 2LMR, 3LMR, $4 \mathrm{LMR}$ and $5 \mathrm{M})$.

Significant whitening was observed in both study groups in all three color measurement tools (Table 5). A bleaching of approximately 7 units on the VITA Classical scale and in the VITA Bleachedguide was observed. For $\triangle E^{*} a b$ and $\triangle E 00$, a change of approximately 10 units and 6 units respectively was observed (Table 5). No significant difference was observed between groups (Table 5). 
Table 5. Means and standard deviations of $\Delta \mathrm{SGU}$ obtained with the Vita Classical and Vita Bleachedguide and $\Delta \mathrm{E} /$ $\Delta$ E2000 obtained by spectrophotometer between baseline $v$ s. 1- month after post bleaching along with the p-value.

\begin{tabular}{|c|c|c|c|c|}
\hline \multirow{2}{*}{$\begin{array}{c}\text { Color evaluation } \\
\text { tool }\end{array}$} & \multicolumn{2}{|c|}{ Groups } & \multirow{2}{*}{ p-value (*) } & \multirow{2}{*}{ Mena difference $(95 \% \mathrm{CI})$} \\
\hline & Ibuprofen/Caffeine & Placebo & & \\
\hline Vita Classical & $6.8 \pm 3.0$ & $7.0 \pm 2.6$ & 0.75 & $0.2(-1.02$ to 1.42$)$ \\
\hline Vita Bleached & $7.9 \pm 3.4$ & $7.7 \pm 2.7$ & 0.80 & $-0.2(-1.53$ to 1.13$)$ \\
\hline$\triangle \mathrm{E} 2000$ & $6.2 \pm 2.9$ & $6.7 \pm 2.6$ & 0.40 & $0.5(-0.70$ to 1.70$)$ \\
\hline$\Delta \mathrm{E}$ & $10.0 \pm 4.6$ & $10.5 \pm 4.2$ & 0.64 & $0.5(-1.41$ to 2.41$)$ \\
\hline
\end{tabular}

* Student t-test.

\section{Adverse effects}

Two patients from the ibuprofen/caffeine group had severe headache after the second bleaching session. We instructed them to stop taking the capsule and the headache disappeared shortly after the discontinuation of the capsules.

One patient from the ibuprofen/caffeine group took $750 \mathrm{mg}$ of acetaminophen (Tylenol, JanssenCilag Farmacêutica), and other 2 patients from the placebo group self-administered $500 \mathrm{mg}$ of dipyrone (Novalgina, Sanofi Aventis Farmacêutica) to alleviate the bleaching-induced TS.

\section{Discussion}

Our preliminary hypothesis was that the association of ibuprofen and caffeine could provide a better relieve of TS than the ibuprofen use alone. These drugs were administered $1 \mathrm{~h}$ before the bleaching to allow a plasma peak of ibuprofen 1 to $2 \mathrm{~h}$ after the first dose administration. Extra doses of the drugs were used every 8 hours for a period of up to 48 hours after the procedure in an attempt to prevent TS during this period.

We believed that a synergic effect could be observed with the combination of these drugs. It was expected that the coadministration of ibuprofen/caffeine and the their administration during $48 \mathrm{~h}$ after bleaching could promote a greater decrease in TS than that observed in previous studies. Most pharmacological effect of caffeine is related to its antagonistic effect on adenosine receptors, mainly the $\mathrm{A} 2 \mathrm{~A}$ receptor. Caffeine competes with adenosine for $\mathrm{A} 2 \mathrm{~A}$ receptor causing its inhibition and leads to antinociception in neuropathic pain, nociceptive, and inflammatory conditions (17). Despite this, caffeine does not alter dopamine release and therefore does not have abuse potential like other adenosine blocking agents, such as cocaine. Caffeine seems to express its direct effect via central blocking of adenosine receptors. It also blocks the peripheral adenosine receptors on sensory afferents as well as inhibits the cyclooxygenase activity at some sites (17). Understanding these effects, leads to renewed interest as a novel option for TS control. However, the caffeine concentration used in this study failed in exerting an effect on the TS prevention. This may be related to the fact that such antinociceptive properties were previously achieved only in doses between 35 and $100 \mathrm{mg} / \mathrm{kg}(12)$.

The coadministration of ibuprofen and caffeine was reported to be effective in other studies $(10,11)$. However, the high absolute risk of TS of both groups (approximately 93\%) found in the present study demonstrates that this combination was not effective to reduce the bleaching-induced TS. Previous studies using the anti-inflammatory ibuprofen post-dental bleaching have also failed to decrease the absolute risk of TS. Charakorn et al. (6) administered a single $600 \mathrm{mg}$ dose of the drug $30 \mathrm{~min}$ before bleaching which led to a reduction in only the intensity of TS during the period of bleaching treatment. Since TS can last for up to $48 \mathrm{~h}$ after bleaching, it would be opportune to administer other doses of the drug after the bleaching period. This was observed in a later study conducted by Paula et al. (3) in which doses of $400 \mathrm{mg}$ of ibuprofen were administered for $48 \mathrm{~h}$ after bleaching, to decrease TS for a longer period. However, this study also observed only the reduction in the intensity of TS in the period of up to one hour after bleaching. At the present study, contrary to what was previously observed (3), the highest intensity of TS in this study, were observed within $1 \mathrm{~h}$ after the in-office bleaching, being considered moderate when evaluated by the NRS scale, and no reduction in intensity was observed in the other evaluation periods.

It worth to mention that, despite a higher concentrated hydrogen peroxide was used in the present study, as well as in the previously ones $(3,6,14)$, there are several differences between in-office bleaching gels that could influence the results of TS $(18,19)$. The specific composition of in-office bleaching gel 
used in the present study could be also responsible for the higher absolute risk of TS (14). Future clinical trials need to be done to evaluate this hypothesis.

The inefficacy of the drugs in this study suggests that there are other mechanisms involved in the bleaching induced TS process. As previously mentioned, systematic reviews of randomized clinical trials demonstrate that used systemic drugs to reduce the TS was not able to reduce the absolute risk of bleaching-induced TS (7-9). It may suggest that oral medicines are not reaching pulp tissue at the same time of the hydrogen peroxide radicals. This can be explained to the fact that pulp tissue is packed in mineralized tissue, which hinders the arrival of the drug to the site, inhibiting the analgesic effect. In addition, some factors such as the presence of the immune system, lymphatic drainage, urinary excretion and the morphological characteristics of the dentin substrate can modulate the amount of drug that reaches plasma, extracellular fluid and pulp chamber and thus interfere in the amount of drug that reaches the pulp of drugs administered orally (20). Although prostaglandins production is inhibited by the ibuprofen use, many other inflammatory mediators, not inhibited by ibuprofen, can be expressed in the pulp chamber and trigger TS (3). This deserves further investigations.

In addition, the lack of efficacy of ibuprofen and caffeine in reducing TS is due to the ability of peroxides to cause the direct activation of TRPA 1 neuronal receptors present in the dental pulp, leading to the detection of harmful stimuli (nociceptors), which would explain the painful sensation during and after dental bleaching. Therefore, the use of agents capable of inactivating TRPA 1 receptors presents in the dental pulp could be a more promising alternative to prevent the bleaching-induced TS (21). Further studies should be conducted to evaluate this condition. To date, the most successful attempt to reduce bleaching-induced TS was achieved after application of desensitizing agents topically (22). For this reason further studies should be conducted with the aim to develop topical desensitizers capable of preventing the depolarization of nerve fibers or the inflammatory response in the pulp tissue.

The degree of whitening achieved with 2 bleaching sessions of in-office bleaching (50-min application of 35\% HP per session), measured with VITA Classical and VITA Bleachedguide scales was approximately 7 and 8 SGU respectively, with no significant difference between groups. Compared to studies that evaluated color changes in incisors, the bleaching efficacy reported in this study was higher because we evaluated color at the middle third of the upper canines $(14,16)$. In bleaching studies, we usually recruit patients with teeth darker than A2. As canines are usually darker than incisors patient recruitment is easier since most young patients have incisors A2 or darker but they do not have incisors this color (16). For instance, at baseline, most participants from this study presented canines shade A3. The darker the teeth the higher the bleaching effect. This explains why a higher degree of whitening was found in this study compared to those that evaluated color change in incisors.

More than one formulae for calculating $\triangle \mathrm{E}$ were used in this study: CIELab $76\left(\Delta \mathrm{E}^{*} \mathrm{ab}\right)$ and CIEDE2000 $(\triangle \mathrm{E} 00)$. Although the latter one is more advanced and it has been recommended by $\mathrm{CIE}$, most of the bleaching studies still report their findings using the CIELab $76(3,16,18)$ the reason why we reported both $\triangle \mathrm{E}$ calculations. The CIEDE 2000 was a system developed to improve the correction between the differences in computed colors and perceived colors (23). According to previous studies, the CIEDE2000 formula presented a better adjustment than the CIELab formula in the evaluation of color difference thresholds in dental ceramics (24) and showed a better estimate for visual perception of color (23). In summary, all instruments used for color evaluation demonstrated that the coadministration of ibuprofen and caffeine did not interfere negatively in the efficacy of dental bleaching with is in line with previous studies that attempted to prevent or reduce bleaching-induced TS by administration of analgesics or anti-inflammatory drugs $(3,6)$.

The coadministration of ibuprofen and caffeine in this study produced adverse effects in only 2 out of the 42 participants in the experimental group. The low rates of side effects observed for this analgesic combination are in accordance to previous literature findings $(10,11)$. The only adverse effect reported by patients was the development of an intense headache. This may be related to caffeine's ability to exert different potent effects depending on the tissue or organ, the dosage and the exposure time (25). In both patients, these symptoms disappeared immediately after discontinuation of the administration of the drugs, and no medical intervention was required.

Finally, the limiting factors should be taken into account about this study. Most of the participants were young adults, and this finding can affect the generalization of study results for the general population. In addition, subjectivity at the time of reporting pain may lead to changes in the observed results. Although the sample size was larger compared to the most studies that evaluated antiinflammatory drugs for TS reduction, the sample size used only allowed the detection of high effect sizes. Therefore, one cannot rule out the fact that smaller effect sizes exist. The use of the same 
experimental project to conduct studies with larger sample sizes should be encouraged. To control adherence to the protocol, we sent cell phone text messages and delivered a form to remind patients of administer their capsules. However, the adherence to the protocol could not be totally controlled, which is a problem of clinical trials that studies the effects of drugs. In conclusion, preoperative coadministration of ibuprofen $400 \mathrm{mg}$ and caffeine $100 \mathrm{mg}$ for a period of $48 \mathrm{~h}$, starting $1 \mathrm{~h}$ before bleaching, did not reduce the absolute risk or intensity of bleaching-induced TS.

\section{Acknowledgments}

This study was performed by Karine Silva as partial fulfillment of his Master of Science degree at the State University of Ponta Grossa (UEPG), Ponta Grossa, PR, Brazil. The authors of this study would like to thank the Coordination for the Improvement of Higher Education Personnel (CAPES), Ministry of Education, Brazil (Finance Code 001) and National Council for Scientific and Technological Development (CNPq) under grant 308286/2019-7.

\section{Resumo}

Este ensaio clínico avaliou o efeito da coadministração de ibuprofeno/cafeína na sensibilidade dental decorrente de clareamento (SD). Um estudo clínico randomizado, paralelo, triplo-cego, foi realizado em 84 pacientes que receberam cápsulas de ibuprofeno/cafeína ou placebo. Os fármacos foram administrados por 48 horas, começando 1 hora antes do clareamento em consultório. Duas sessões de clareamento foram realizadas com gel de peróxido de hidrogênio 35\% com intervalo de 1 semana. A SD foi registrada até 48 horas após o clareamento dental com uma escala visual analógica (VAS) de 0-10 e uma escala de classificação numérica (NRS) de 5 pontos. A cor foi avaliada com as escalas Vita Classical e Vita Bleachedguide ( $\triangle \mathrm{SGU}$ ) e com o espectrômetro Vita Easyshade ( $\triangle \mathrm{E}^{*}$ ab e $\triangle \mathrm{E} 00$ ). 0 risco absoluto de SD em ambos os grupos foi avaliado por meio do teste exato de Fischer. As comparações da intensidade da SD (NRS e VAS) foram realizadas utilizando-se o teste Mann-Whitney e uma ANOVA de dois fatores com medidas repetidas, respectivamente. A alteração de cor entre os grupos foi comparada com a o teste t de Student. 0 nivel de significância foi de $5 \%$. Não houve diferença estatisticamente significante entre os grupos para o risco absoluto de SD $(p=1,00)$ ou para a intensidade de SD $(p>0,05)$. Observou-se clareamento de aproximadamente 7 unidades nas escalas Vita Classical e Vita Bleachedguide, sem diferença estatística entre os grupos. Concluiu-se que a coadministração de ibuprofeno e cafeina não reduziu o risco absoluto ou intensidade da SD e não interferiu na eficácia do clareamento dental. 


\section{References}

1. Da Costa JB, McPharlin R, Paravina RD, Ferracane JL. Comparison of at-home and in-office tooth whitening using a novel shade guide. Oper Dent. 2010;35:381-388.

2. Gurgan S, Cakir FY, Yazici E. Different light-activated in-office bleaching systems: A clinical evaluation. Lasers Med Sci. 2010;25:817-822.

3. Paula $E$, Kossatz $S$, Fernandes D, Loguercio $A$, Reis $A$. The effect of perioperative ibuprofen use on tooth sensitivity caused by in-office bleaching. Oper Dent. 2013;38:601-608.

4. Mehta $D$, Venkata $S$, Naganath $M$, Lingareddy $U$, Ishihata $H$, Finger WJ. Clinical trial of tooth desensitization prior to in-office bleaching. Eur J Oral Sci. 2013;121:477-481.

5. Silva-Costa RSG, Ribeiro AEL, Assunção IV, Júnior RFA, Araújo AA, Guerra GCB, Borges BCD. Inoffice tooth bleaching with $38 \%$ hydrogen peroxide promotes moderate / severe pulp inflammation FGF-2 and osteocalcin in rats. J Appl Oral Sci. 2018;26:1-9.

6. Charakorn $P$, Cabanilla LL, Wagner WC, Foong W-C, Shaheen J, Pregittzer R, Schneider D. The effect of perioperative ibuprofen use on tooth sensitivity caused by in-office bleaching. Oper Dent. 2009;34:131-135.

7. Almassri HNS, Zhang 0 , Yang $X, W u X$. The effect of oral anti-inflammatory drugs on reducing tooth sensitivity due to in-office dental bleaching: A systematic review and meta-analysis. J Am Dent Assoc. 2019;150:e145-157

8. Carregosa Santana ML, Leal PC, Reis A, Faria-e-Silva AL. Effect of anti-inflammatory and analgesic drugs for the prevention of bleaching-induced tooth sensitivity: A systematic review and meta-analysis. J Am Dent Assoc. 2019;150:818-829

9. Costa RTF, Moraes SLD, Lemos CAA, Souto Maior JR, Vasconcelos BC do E, Pellizzer EP. Effect of Analgesic Drugs on Tooth Sensitivity Induced by In-office Dental Bleaching: A Systematic Review and Meta-analysis. Oper Dent 2020;45:E66-E76.

10. Diamond S, Balm TK, Freitag FG. Ibuprofen plus caffeine in the treatment of tension type headache. Clin Pharmacol Ther. 2000;68:312-319.

11. Weiser T, Richter E, Hegewisch A, Muse DD, Lange R. Efficacy and safety of a fixed dose combination of ibuprofen and caffeine in the management of moderate to severe dental pain after third molar extraction. Eur J Pain 2018;22:28-38

12. Sawynok J. Caffeine and pain. Pain. 2011;152:726-729.

13. Pandis B, Chung B, Scherer RW, Elbourne D AD. CONSORT 2010 statement : extension checklist for reporting within person randomised trials. Br J Dermatol. 2019;180:534-52.

14. Maran BM, Vochikovski L, Hortkoff DRA, Stanislawczuk R, Loguercio AD, Reis A. Bleaching sensitivity with a desensitizing in-office bleaching gel: a randomized double-blind clinical trial. Quintessence Int. 2020;8:2-11.

15. Sepkowitz KA. Energy drinks and caffeine-related adverse effects. J Am Med Assoc. 2012;309:243-244..

16. Maran BM, Vochikovski L, Hortkoff DRA, Stanislawczuk R, Loguercio AD, Reis A. Tooth sensitivity with a desensitizing-containing at-home bleaching gel - a randomized triple-blind clinical trial. J Dent 2018;72:64-70.

17. Baratloo A, Rouhipour A, Forouzanfar MM, Safari S, Amiri M, Negida A. The role of caffeine in pain management: $A$ brief literature review. Anesthesiol Pain Med 2016;6: e33193.

18. Loguercio AD, Servat $F$, Stanislawczuk $R$, Mena-Serrano A, Rezende $M$, Prieto MV, Cereño $V$, Rojas MF, Ortega K, Fernandez E, Reis A. Effect of acidity of in-office bleaching gels on tooth sensitivity and whitening: a two-center double-blind randomized clinical trial. Clin Oral Investig. 2017;21:28112818.

19. Basting RT, Amaral FLB, França FMG, Flório FM. Clinical comparative study of the effectiveness of and tooth sensitivity to $10 \%$ and $20 \%$ carbamide peroxide home-use and $35 \%$ and $38 \%$ hydrogen peroxide in-office bleaching materials containing desensitizing agents. Oper Dent. 2012;37:464-473.

20. Loguercio AD, Martins $L M$, da Silva $L M$, Reis A. In-Office Whitening. In Tooth Whitening An Evidence-Based Perspect. Jorge Perdigão (Editor). 1st ed. Springer; 2016. p 145-167.

21. Markowitz K. Pretty painful: Why does tooth bleaching hurt? Med Hypotheses. 2010;74:835840.

22. Tay LY, Kose C, Loguercio AD RA. Assessing the Effect of a Desensitizing Agent Used Before Inoffice Tooth Bleaching. J Am Dent Assoc. 2009;140:1245-1251.

23. Pecho $O E, G$ hinea $R$, Alessandretti $R$, Pérez $M M$, Della Bona $A$. Visual and instrumental shade matching using CIELAB and CIEDE2000 color difference formulas. Dent Mater. 2016;32:82-92. 


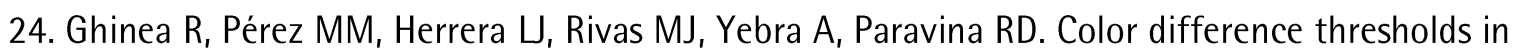
dental ceramics. J Dent. 2010;38:57-64.

25. Shapiro RE. Caffeine and headaches. Curr Pain Headache Rep. 2008;12:311-315.

Received: 01/12/2020

Accepted: 31/05/2021 